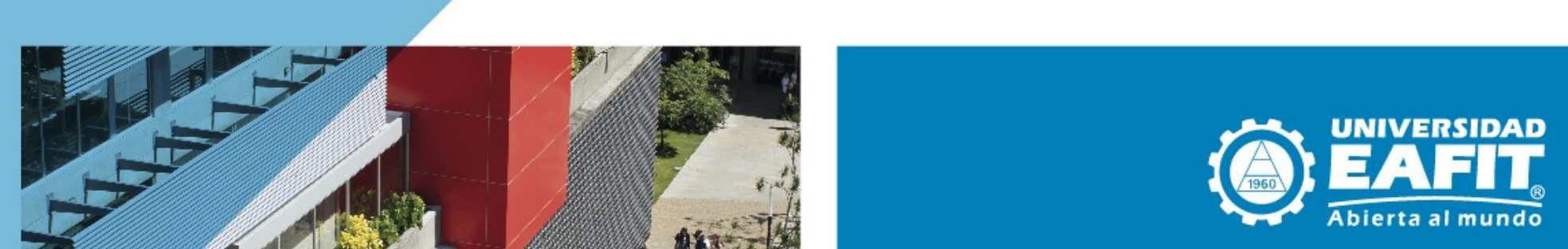

Escuela de Economía y Finanzas

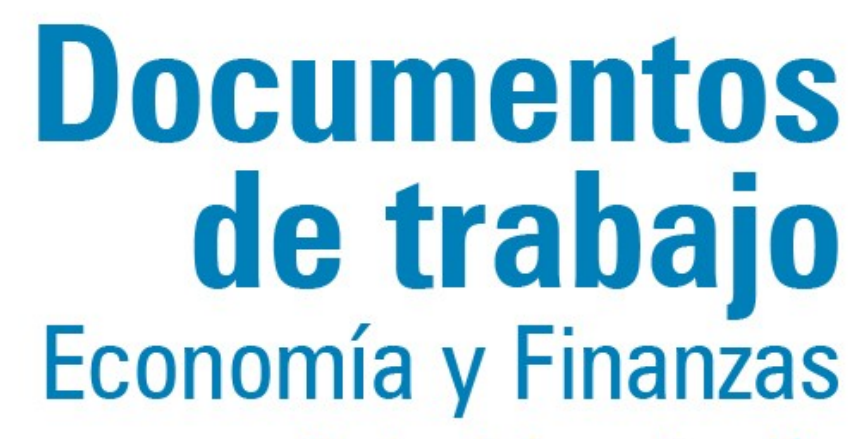

Centro de Investigación Económicas y Financieras

No. 17-12 National Culture, Familles, or Education Policies:

2017 What Determines National Test Scores?

Theodore R. Breton

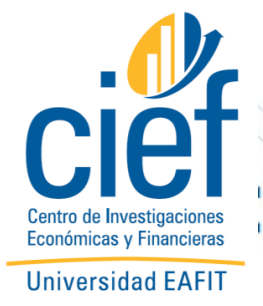




\title{
National Culture, Families, or Education Policies: What Determines National Test Scores?
}

\author{
Theodore R. Breton*
}

June 18, 2017

\begin{abstract}
Conventional analyses attribute cross-country differences in students' average test scores to family characteristics, school resources, and school system characteristics, but institutional economists and cultural anthropologists argue that cultural beliefs and institutions are the fundamental determinants of a society's level of human capital. I examine the effects of cultural beliefs, institutional characteristics, family characteristics, and various school and education policy characteristics on average PISA scores in mathematics. I find that national cultural and institutional characteristics explain over $80 \%$ of the variation in average scores across 58 countries. When family, school, and school system characteristics are included as causes, cultural and institutional characteristics continue to explain most of the variation in average scores. More financial resources for schools continue to raise average scores, the existence of a central exit exam has a small effect, and the share of private enrollment in the school system has no effect on these scores.
\end{abstract}

JEL Codes: $\quad$ 121, 015, Z19

Key Words: Test Scores, Culture, Institutions, Education, PISA, World

*Universidad EAFIT, ted.breton@gmail.com 


\section{Introduction}

An increasing number of countries participate in international tests of their students' cognitive skills. The results show the enormous variation in students' average skills across countries. On the PISA 2015 test of mathematics, the average score ranged from 328 in the Dominican Republic to 569 in Singapore. ${ }^{1}$

Researchers have analyzed students' test scores for decades to determine why skill levels vary so much. The standard conclusion is that individual scores vary due to the effects of families, peers, schools, and student ability [Hanushek and Woessmann, 2008]. At the country level Fuchs and Woessmann [2007] present evidence that average scores on PISA 2000 tests are higher where parents are more educated, where schools have more resources and are privately operated, and where the school system requires a central exit exam. Juerges and Schneider [2004] present evidence that average scores on TIMSS 1995 are higher where parents are more educated and schools have more resources, but they do not find any effect from central exit exams.

Even though family and school characteristics are correlated with a country's average scores, there is reason to suspect that these characteristics are not their principal determinants. Hanushek and Woessmann [2008] document that across the world in response to numerous types of school initiatives, student achievement has been remarkably resistant to improvement. The implication is that something beyond families and the schools determines a country's average student achievement.

The economic development and cultural anthropology literatures provide alternative theories to explain national differences in student achievement. North and Thomas [1973] distinguish between the proximate and the fundamental causes of economic development. They argue that physical and human capital are the proximate determinants of economic growth, but a society's institutions, and particularly its protection of property rights, determine whether physical and human capital are created. North [1990] argues that institutions, i.e., the formal and informal rules for human behavior, create the political, social, and economic incentives that determine human behavior in each society. Organizations and individuals operate within the institutional framework that characterizes each society. According to this theory, a country's

\footnotetext{
${ }^{1}$ Public interest in a country's average score on international tests has increased because there is evidence that higher scores raise a country's economic growth rate, at least in countries with low average scores [See Hanushek and Woessmann, 2012 and Breton, 2015].
} 
institutions are the fundamental determinants of its level of human capital, which includes its students' average level of skills.

Following North's lead, Acemoglu, Johnson, and Robinson [2006] argue that human capital, which they measure with adults' average level of schooling, is higher in countries that have more inclusive political institutions. Their argument is that countries with inclusive political institutions create economic institutions that provide security for private property and access to economic resources for a substantial portion of their citizens. In an inclusive environment, citizens have the incentive and the means to invest in physical and human capital and become economically successful. Acemoglu, Gallego, and Robinson [2014] argue that societies with more inclusive institutions provide more schooling to their members. So from the institutionalist perspective, cross-country differences in average test scores are the end result of the differences in the political and economic institutions that determine human behavior in each country.

Cultural anthropologists broaden the determinants of human behavior beyond political and economic institutions to include cultural beliefs. North's definition of Institutions includes cultural norms, which are the practices that accompany cultural beliefs. Hofstede and Hofstede [2005] argue that a society's culture and institutions are inter-related. When attempts are made to impose new institutions (i.e., new rules or norms) on a society, these institutions change in response to the existing cultural beliefs, but they also affect these beliefs. Societies with similar cultural beliefs can have somewhat different institutions, if they have a different historical experience. As a consequence, a society's cultural beliefs and its institutions could both affect its students' average test scores.

In this paper I first describe the channels through which cultural and institutional characteristics affect student, family, and school behavior and ultimately determine students' average skills in each country. Subsequently, I analyze whether cultural and institutional characteristics explain cross-country differences in average scores on PISA 2012 and 2015 tests of mathematics. I find that either cultural beliefs or a measure of institutional characteristics can explain more than half of the cross-country variation in students' average scores across 58 countries and that a combination of these measures explains over $80 \%$ of the variation in these scores.

If cultural and institutional characteristics are the fundamental determinants of student achievement, then independent efforts within the schools to raise students' average test scores would have a limited effect because the cultural and institutional characteristics continue unchanged. I test this hypothesis by estimating the effects of combinations of institutional, cultural, family, and school characteristics and the existence of a central exit exam on average test scores. I find that when institutional and cultural characteristics are included in a model with family and school characteristics, they continue to have a larger effect on average scores than all 
of proximate factors combined and that the effect of central exit exams is small and not statistically significant.

These findings do not mean that individual schools and teachers cannot have a positive effect on individual student achievement. Indeed, schools and teachers constantly work to improve student outcomes. Rather, the implication is that in the aggregate the characteristics of the national culture, operating through the practices in families and in the schools, are the principal determinants of student achievement. Schools have very little independent capability to raise students' average scores because they act as agents of the larger culture, as do the students' families. This means that in countries where students' average scores are high, the culture and institutions provide strong incentives to achieve high scores. Schools and families respond to these incentives by exerting unrelenting pressure on students to achieve high scores.

The rest of this article is organized as follows: Section II presents the hypothesis in more detail. Section III specifies the model and the data used to test the hypothesis. Section IV presents the results. Section $\mathrm{V}$ concludes.

\section{The Hypothesis}

A priori it is evident that cultural beliefs and practices must affect student learning, at least to some degree. Motivation is critical in determining whether a student learns. As an example, in low-income countries poor urban students often choose whether to achieve cognitive skills in school or to participate in criminal gangs. Rich students choose whether to focus on achieving cognitive skills or on cultivating relationships with members of their social class. The choices they make depend on the culture (i.e., the societal beliefs about what is proper) and the institutions in their country because these factors determine whether the achievement of cognitive skills leads to much economic and social success. The potential rewards from achieving these skills in each country affect the effort that students and their families make to achieve high test scores.

Dang and Rogers [2008] document the substantial commitments that families make to provide private tutoring for their children in some countries. The commitment to private tutoring is entirely voluntary and is separate from the educational activity within the schools. This family commitment must be due to the cultural and institutional characteristics of these societies, which evidently provide either particularly high social and/or economic rewards for the achievement of high test scores, or particularly severe penalties for the failure to achieve high scores.

The conventional explanations of the determinants of student test scores do not iclude the effects of culture and institutions. Instead they examine the effects of family and school characteristics, which are the proximate determinants of these scores. Fuchs and Woessmann [2007] perform a principal components' analysis of the effects of five categories of factors on 
average PISA 2000 scores in 32 countries. They show that when included alone, the family characteristics category has the largest effect, explaining $49 \%$ of the variation in average mathematics scores across countries. The parents' level of schooling, which they assume has a uniform effect across countries, is a particularly influential component of these characteristics.

Figure 1 shows the relationship between average test scores on the PISA tests of mathematics in 2012 and/or 2015 and the average schooling attainment of adults age 35-40 in 2010. These adults have the approximate age of the parents of the students that took the PISA tests in 2012 and 2015. The schooling data are taken from Barro and Lee [2013].

Figure 1

Average Scores on PISA Tests vs. Adults' Average Schooling Attainment

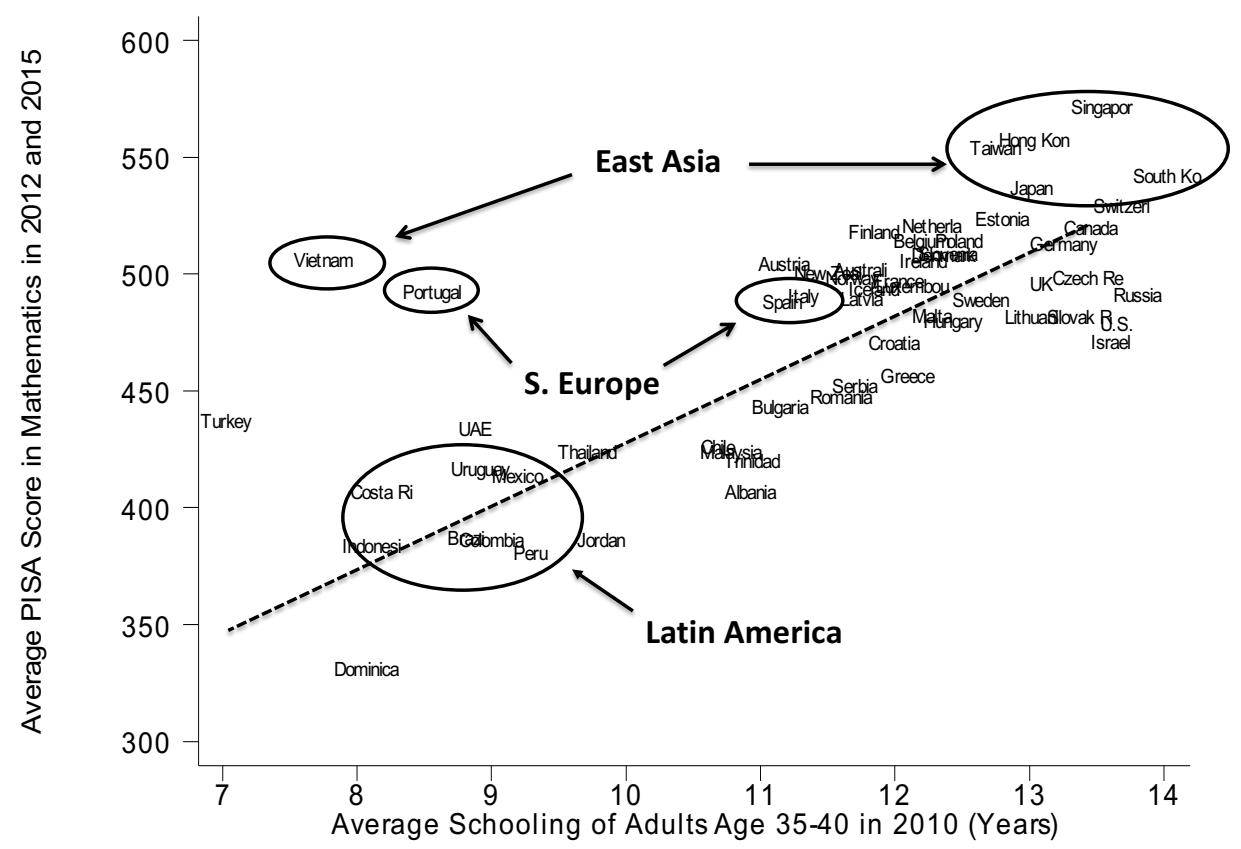

The pattern in the data shows that there is a high correlation $(\rho=0.73)$ between the students' average scores and the average schooling of adults their parents' age. This correlation is consistent with the relationship consistently found between parental education and student scores on the international tests.

Nevertheless, certain patterns in the data indicate that cultural characteristics also affect average scores. The East Asian countries have average test scores that are substantially higher than other countries that have the same average levels of adult schooling. Portugal, which has an unusually low average level of adult schooling for Europe, has average test scores that are 
similar to the average scores in the other Catholic Mediterranean countries. Average scores are considerably lower but quite similar in all the countries in Latin America.

Many countries in East Asia have had a long exposure to the dominant Chinese culture in the region, in which government officials have been selected by examination for over a thousand years. These countries have adopted this ancient practice to determine which students should be selected for more advanced study, or for entry into the most prestigious schools, which subsequently determines access to the most prestigious organizations after graduation.

A societal emphasis on standardized testing for advancement creates an enormous incentive for families to pressure their children to work hard, perhaps excessively hard, to achieve high scores. As a consequence, most families in East Asian countries that have a Confucian tradition send their children for private tutoring, and in South Korea families expend almost 3\% of GDP on this activity [Dang and Rogers, 2008]. This heavy societal emphasis on test results is effective in raising student achievement, as demonstrated by the unusually high PISA scores in many East Asian countries. Even Vietnam, which is a very poor country with low average levels of adult schooling, has impressively high average scores on the PISA mathematics test.

Breton and Canavire-Bacarreza [2017] investigate why Latin American countries had average scores on the PISA 2012 mathematics test that are 100 points below the average scores in Scandinavian countries. Families in Latin America have a much lower average level of schooling. But in addition, they show that the parents' level of education in Latin America has a much smaller effect on their children's scores than in Scandinavia. They also document that families in Latin America have far fewer books in the home than other countries with the same levels of GDP/adult or average schooling. This difference explains about 25 points of the lower average PISA scores in this region compared to other regions. Breton and Canavire-Bacarreza argue that the low number of books is a cultural effect, likely related to the restrictive religious controls on the publication and importation of books in Latin America prior to independence from Spain and Portugal.

Perhaps more importantly, a country's culture and institutions explain the average level of adult schooling in the population. Schools have existed for thousands of years, but the schooling of the masses did not begin until the $19^{\text {th }}$ century [Easterlin, 1981]. Countries in which adults have a high average level of schooling today provided substantial schooling to the masses much earlier than other countries. The willingness to provide this schooling depended in part on the perceived importance of educating the poor in each culture [Breton, 2013].

\section{The Model and the Data}

Schools are a societal institution, which have as one of their objectives the transfer of societal beliefs and practices to the next generation [Bowen, 1986]. Public schools are directly 
under the control of the government, and in democratic societies they also are guided formally and informally by parents and other citizens. Public schools are more accountable to political organizations, while private schools are more accountable to religious organizations or to parents. But regardless of their ownership structure, all schools must operate in ways that are acceptable to the religious authorities, political authorities, and parents in each country.

Conceptually, the relationships between the culture, the political and religious organizations, the educational system, families, and student achievement can be modeled as shown in Figure 2. Since the political or religious organizations that manage schools are composed of individuals who in the aggregate have the cultural beliefs characteristic of their society, the behavior of these organizations is itself affected, if not entirely determined, by the societies' particular cultural beliefs and institutions.

Figure 2

\section{Societal Determinants of Students' Average Test Scores}

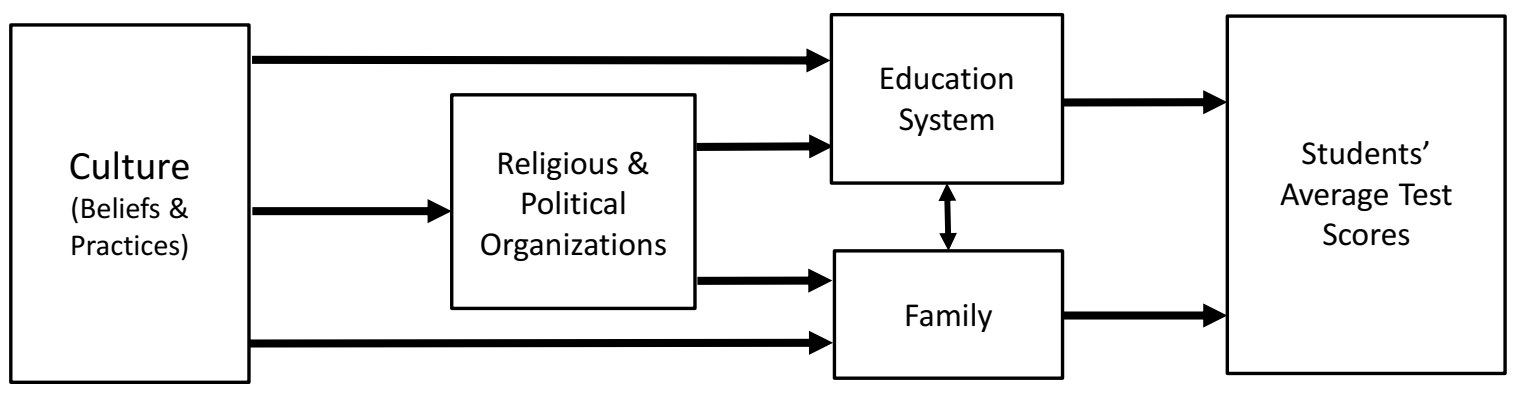

The average level of student achievement is determined by the operation of the societal system that manages children and affects their behavior. In this process schools have a large role, but their operation is constrained by the other components of the system. The schools' effort to train students is a joint activity with the students' families, who may supplement their own efforts with private tutoring and other private instruction.

As implied in the figure, schools manage children in ways that are acceptable to society, whether through the form of discipline, or the teacher-student relationship, or the hours inside and outside of school that children are expected to dedicate to their studies. Outside forces, such as foreign educational practices, may influence domestic practices, but these practices are unlikely to be accepted or successful if they are inconsistent with the domestic culture.

Student achievement of high average test scores is difficult and requires enormous effort on the part of the students and their parents. The amount of effort expended is 
determined by the motivation of the students and their parents to make this effort, which is largely outside the control of the schools. This motivation is determined by the characteristics of the culture, which determine the importance of student learning for social and economic success. This importance is evident in the benefits that society provides students for mastering cognitive skills, either through awards and recognition, or by providing access to additional or more prestigious schooling and subsequently to higher-status careers or better-paying jobs.

Culture in this model includes both the society's beliefs and its practices. If the culture includes the belief that merit should determine schooling and work opportunities, then the educational institutions will set up processes to implement these beliefs, such as centralized examinations, and the schools and families are likely to respond to these incentives by pressuring students to achieve high test scores. In the absence of these incentives, the students are unlikely to achieve such high scores.

The level of rewards a society provides its students for scholastic achievement is related to the inclusiveness of its institutions. Societies with more inclusive institutions are more likely to select individuals for further study or for desirable jobs based on merit, while societies with less inclusive institutions are more likely to make these selections based on social relationships. In societies that function based on social relationships, there is little material benefit to students and families from expending intensive effort to achieve high scores on standardized tests, so we should not expect that students in countries less inclusive institutions would score highly.

Other researchers have investigated the relationship between certain elements of the conceptual model shown in Figure 2. French, French, and Li [2015] show that cultural characteristics affect expenditures on education, which then affect average scores on PISA tests. Zhang, Khan, and Tahirsylaj [2015] categorize countries into cultural clusters based on the variance in average PISA test scores across schools within countries and then show that these cultural clusters explain about half of the variation in average test scores across countries.

\section{2a Model of the Effect of Culture on Average Test Scores}

In this analysis I examine how well the cross-country variation in average test scores can be explained by societal, educational, and family characteristics, so the mathematical model is quite simple:

\section{1) $\quad$ AvgScore $_{i}=\alpha_{0}+\sum \alpha_{j} X_{i j}+\varepsilon_{i}$}

AvgScore represents the average score on the PISA mathematics test in each country $\mathrm{i}$ and $\mathrm{X}$ represents the set of each country's j characteristics. Since these characteristics are the fundamental and/or the proximate causes of the creation of human capital in each country, there are no control variables in the model. 
The average score is the national score on the mathematics test in PISA 2012 and/or PISA 2015. I use the average of the two scores when both are available. Since each set of scores includes some error as the true measure of students' average skills, this error is likely to be lower in the average score from two tests. Since average scores, cultural beliefs, and institutional characteristics change very slowly, there is no reason to expect that any change in the average scores over this three-year period is due to changes in the independent variables. Using scores from both years also permits the inclusion of several countries in the data set that did not participate in both tests, which increases the number of less educated countries in the sample. As described below, I use a combination of variables to define a country's culture, educational, and family characteristics.

\section{2c Measures of Cultural Characteristics}

Numerous researchers have attempted to identify and measure a society's cultural characteristics. These characteristics are measures of individuals' beliefs about how individuals should behave in society. Since these beliefs are somewhat amorphous, there is no unique way to define or categorize a society's set of beliefs. Different researchers have created different categories of measures to characterize these beliefs.

Geert Hofstede created a set of five cultural characteristics to explain individual beliefs or behavior across a wide variety of cultures [Hofstede and Hofstede, 2005]:

1. Power Distance (Accept that society is hierarchical and hierarchy confers authority)

2. Individualism/collectivism (Accept that the individual, not the group, makes decisions)

3. Masculinity/femininity (Success-oriented rather than relationship-oriented)

4. Uncertainty Avoidance (Comfortable with strict societal beliefs and rules)

5. Long-term Orientation (Willing to sacrifice short term to achieve future rewards)

These five characteristics emerged using principal factor analysis from answers to a large array of questions about beliefs among IBM sales executives in many countries. As such, they represent the beliefs of the middle rather than the lower classes, which likely correspond to the beliefs of the individuals that direct a country's political and economic institutions. The first four characteristics were identified in Western cultures, while the fifth characteristic emerged from comparing Western and Eastern, particularly Asian, cultures. Factor analysis also indicated that these five characteristics include the principal cultural characteristics identified as important by other anthropologists [Hofstede and Hofstede, 2005].

I use Hofstede's set of cultural characteristics rather than another set because his system has been applied to almost all of the countries that participated in the PISA tests. For each country I obtained its rating for each of the five cultural belief categories from the Hofstede web site: https://www.geert-hofstede.com/national-culture.html. These ratings are based on 
surveys undertaken between 1967 and 1973 in a core group of countries and then extended to other countries over time.

Cultural beliefs change, so they are endogenous in the economic development process. Hofstede and Hofstede [2005] argue, however, that even if beliefs change somewhat over time, the large differences in beliefs between societies are relatively stable, so ratings developed years ago continue to have validity as a measure of a society's cultural beliefs compared to other countries. As an example, Latin American countries have similar cultural beliefs today even though they have been politically independent for about 200 years.

\section{2b Measures of Institutional Characteristics}

Societies can also be described by their institutional characteristics. Acemoglu, Johnson, and Robinson [2006] argue that countries with more inclusive political institutions create economic institutions that provide their members with incentives to invest in physical and human capital. They use an index of the perceived risk of expropriation as their measure of institutions. Acemoglu, Gallego, and Robinson [2014] and numerous other researchers have used an index of commitment to the Rule of Law as their measure of institutions. These two indices are highly correlated, but the Rule of Law measure is more reliable because there are more objective ways to measure the operation of the judicial system than the probability that the executive may expropriate private property. According to the World Bank on its web site, the Rule of Law Index “...captures perceptions of the extent to which agents have confidence in and abide by the rules of society, and in particular the quality of contract enforcement, property rights, the police, and the courts, as well as the likelihood of crime and violence."

Acemoglu, Gallego, and Robinson [2014] argue that the Rule of Law index provides a broad measure of a country's institutions. This index implicitly measures the relative inclusivity of the country's institutions. Countries with a higher commitment to the rule of law treat citizens more equally, which corresponds to a set of formal and informal ways of doing things that provide more equal opportunities for all. This index measures much more than the characteristics of a country's judicial operations. In societies with high adherence to the rule of law, social status is a less important determinant of whether individuals can progress irrespective of their social class. More inclusive societies provide greater rewards to individuals based on their capability to contribute to the economy, which provide an incentive for students to develop useful skills and for families to encourage them to learn these skills.

Countries more committed to the rule of law are more egalitarian, so they tend to be more willing to provide public funds for the schooling of their citizens. Since societal beliefs change slowly over long periods, the adults in these countries are likely to have received more 
schooling when they were children, which enables them to provide more assistance to their own children in their acquisition of useful skills.

This line of argument provides one explanation for the high correlation between adult schooling and students' test scores in Figure 1. In this view higher average schooling and higher test scores are both the result of long-standing cultural and institutional characteristics that support the acquisition of human capital.

The World Bank's index for the Rule of Law extends from -2.5 to 2.5. I convert this index to one that has values between 0 and 1 by adding 2.5 and dividing by 5 . Figure 3 shows that average adult schooling at age 35-40 years is correlated across countries with this modified Rule of Law index $(\rho=0.56)$.

\section{Figure 3}

Adults' Average Schooling in 2010 vs. the Rule of Law in 2013

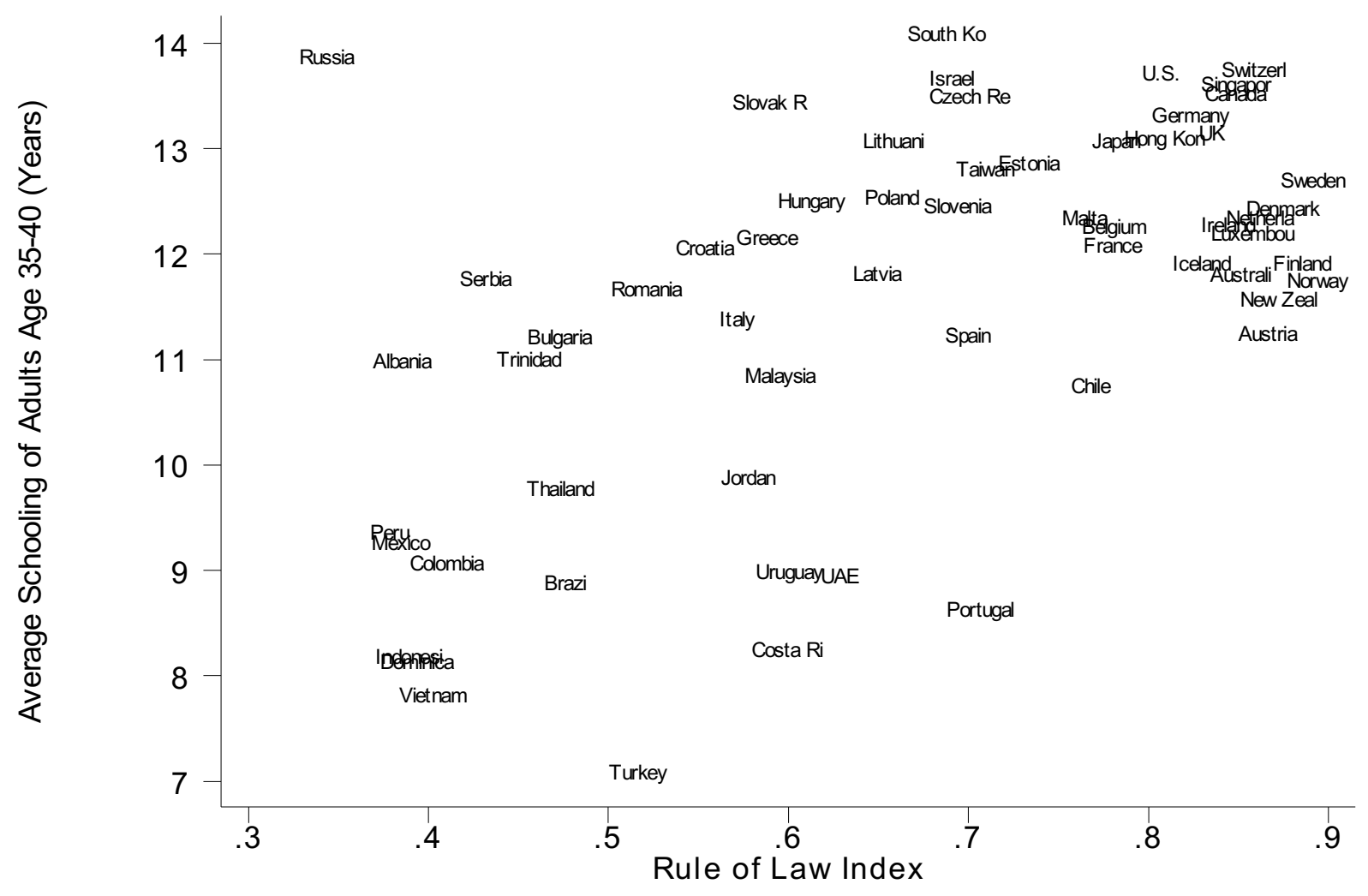

\section{2c The Link Between Culture and Institutional Characteristics}

Klasing [2013] argues that it is hard to think of a country's culture (i.e., its shared values and beliefs) as distinct from its institutions (i.e., the formal and informal rules that regulate 
human interaction). Since institutions are composed of individuals, they must operate in a fashion that is consistent with the society's cultural beliefs. But institutions are also affected by political and military developments, so countries that have similar cultural beliefs (e.g., countries in Latin America) may have somewhat different institutions based on each country's particular history.

Societies that have a low Rule of Law index (i.e., a low commitment to the rule of law) have cultural beliefs that permit government bodies to treat individuals differently depending on their social status. Klasing [2013] examines a range of potential cultural characteristics and shows that two of Hofstede's characteristics, Individualism and Acceptance of hierarchy, explain $50 \%$ of the difference in several measures of the quality of government institutions, which are highly correlated with the Rule of Law index. Individualism has a positive effect and Acceptance of hierarchy has a negative effect on the quality of government institutions. Licht, Godschmidt, and Schwartz [2007] present similar evidence connecting Collectivism and Acceptance of hierarchy to the World Bank's Rule of Law index.

Given that Hofstede's two cultural characteristics explain only half of the cross-country variation in the measure of institutions, it seems that either societies' cultural beliefs have not been adequately characterized, the measures of these beliefs are not sufficiently accurate to entirely explain a country's institutional characteristics, or a country's institutional characteristics are an important element of its culture but somewhat distinct from individuals' cultural beliefs. Regardless of which is correct, the implication is that a more complete description of a country's culture includes both its cultural beliefs and its institutional characteristics.

\section{2d Religion as a Measure of Culture}

Historically societies have been defined to a considerable degree by their adherence to a particular religion. Although religion has lost influence in many societies, adherence to a particular religion still defines or affects many cultural beliefs, including individualism, acceptance of hierarchy, and uncertainty avoidance. It seems reasonable to examine whether adherence to the world's major religious ideologies can explain a country' average test scores.

In this investigation I examine the effect of three religious traditions that are widely spread: Protestant, Catholic, and Muslim. Other traditions that are less widely spread, such as Orthodox Christianity, Judaism, Buddhism, Hinduism, and atheism, constitute the base against which the effect of these three traditions are measured. The variables in the model are the share of the population adhering to each of these religions in 1980, taken from La Porta, Lopez-deSilanes, Shleifer, and Vishny [1999], who obtained the data from Barrett [1982]. I also identify the East Asian countries that have a Confucian tradition with a dummy variable.

\section{2e Family and School Characteristics}


Fuchs and Woessmann [2007] show that family, school, and school system characteristics are influential in determining a country's average test scores. I include variables for each of these sets of characteristics. I represent family characteristics with the average schooling of the adults age 35-40 in each country in 2010. This variable is similar to the average schooling of the parents of the 15-year-old students presenting the PISA test in 2012 and 2015 . This is the same variable shown in Figure 1.

I employ two variables to represent the level of financial resources provided to the schools. The first variable is the pupil-teacher ratio in primary school in 2012, which I obtained from the UNESCO web site. The second variable is the share of GDP provided for pre-tertiary public education in 2012 divided by the share of the population under 15 years of age in 2010. This variable is a measure of the relative public expenditures/student in each country. I calculate the share of GDP provided for pre-tertiary schooling from statistics on total public investment in schooling and the share for tertiary schooling on the UNESCO web site. I calculate the share of the population under 15 from data on GDP/capita and GDP/equivalent adult in Penn World Table 7.1 [Heston, Summers, and Aten, 2012].

I employ two variables to describe the institutional characteristics of the school system, the existence of a central exit exam and the share of secondary school enrollment in private schools. I obtain information about the existence of the central exit exam from Leschnig, Schwerdt, and Zigova [2016] and Bol, Witschge, Van de Werfhorst and Dronkers [2014] and elsewhere for the countries not included in these sources. I obtain the private share of secondary enrollment in 2012 from the UNESCO web site. The key data are provided in the Appendix.

\section{Results}

Table 1 presents the results from models that investigate the relationship between average test scores and a series of cultural and institutional characteristics. Column 1 presents the results with Hofstede's five cultural characteristics. Overall the five characteristics explain $57 \%$ of the variation in average test scores, but only Long-Term Orientation is statistically significant at the $5 \%$ level.

In the statistical relationship between the average test scores and the five cultural characteristics, the East Asian countries with a Confucian tradition are outliers, in that they have much higher scores than other countries with similar cultural characteristics. This same situation is evident in Figure 1, where these same countries have average scores that are not explained by the average level of adult schooling. The implication is that an additional cultural factor is required to explain average scores in these countries, namely their Confucian tradition.

Column 2 presents the results of the model that includes a dummy variable for the countries with a Confucian tradition, most of which have substantial Chinese populations. The 
dummy variable is highly statistically-significant and explains 96 points of the PISA test scores. Overall this model explains $74 \%$ of the variation in average test scores, and three of Hofstede's cultural characteristics are statistically significant at the $5 \%$ level.

\begin{tabular}{|c|c|c|c|c|c|c|c|c|}
\hline \multicolumn{9}{|c|}{$\begin{array}{c}\text { Table } 1 \\
\text { The Effect of Culture and Institutions on Average Test Scores } \\
\text { (Dependent variable is the average score on PISA } 2012 \text { and/or 2015) }\end{array}$} \\
\hline & 1 & 2 & 3 & 4 & 5 & 6 & 7 & 8 \\
\hline Sample & 58 & 57 & 58 & 60 & 60 & 58 & 58 & 58 \\
\hline Individualism & $\begin{array}{c}46.5 \\
(27.2) \\
\end{array}$ & $\begin{array}{c}126.0 * \\
(25.6)\end{array}$ & $\begin{array}{c}138.4^{*} \\
(17.4)\end{array}$ & & & $\begin{array}{l}67.6^{*} \\
(24.6) \\
\end{array}$ & $\begin{array}{c}48.3^{* *} \\
(21.4)\end{array}$ & $\begin{array}{c}45.7 \\
(23.4)\end{array}$ \\
\hline $\begin{array}{l}\text { Power } \\
\text { Distance }\end{array}$ & $\begin{array}{l}-62.7 \\
(30.5) \\
\end{array}$ & $\begin{array}{l}-26.9 \\
(24.9) \\
\end{array}$ & & & & $\begin{array}{c}17.0 \\
(22.7) \\
\end{array}$ & & \\
\hline Masculinity & $\begin{array}{l}-15.0 \\
(22.8) \\
\end{array}$ & $\begin{array}{c}-37.2^{* *} \\
(18.4)\end{array}$ & $\begin{array}{c}-41.0 * * \\
(17.5)\end{array}$ & & & $\begin{array}{l}-18.7 \\
(15.8) \\
\end{array}$ & & \\
\hline $\begin{array}{l}\text { Uncertainty } \\
\text { Avoidance }\end{array}$ & $\begin{array}{l}-30.8 \\
(21.8)\end{array}$ & $\begin{array}{c}15.7 \\
(19.0)\end{array}$ & & & & $\begin{array}{c}19.0 \\
(15.9)\end{array}$ & & \\
\hline $\begin{array}{l}\text { Long Term } \\
\text { Orientation }\end{array}$ & $\begin{array}{c}137.2^{*} \\
(21.1)\end{array}$ & $\begin{array}{l}68.0 * \\
(20.6)\end{array}$ & $\begin{array}{l}67.6 * \\
(18.6)\end{array}$ & & & $\begin{array}{l}61.6^{*} \\
(17.3)\end{array}$ & $\begin{array}{l}72.5^{*} \\
(15.6)\end{array}$ & $\begin{array}{l}72.6^{*} \\
(15.6)\end{array}$ \\
\hline $\begin{array}{l}\text { Confucian } \\
\text { Tradition }\end{array}$ & & $\begin{array}{l}96.9 * \\
(17.0)\end{array}$ & $\begin{array}{l}95.6 * \\
(14.6)\end{array}$ & & $\begin{array}{l}68.8^{*} \\
(12.7)\end{array}$ & $\begin{array}{l}71.4^{*} \\
(15.1)\end{array}$ & $\begin{array}{l}60.2^{*} \\
(13.4)\end{array}$ & $\begin{array}{l}59.2^{*} \\
(13.9)\end{array}$ \\
\hline Rule of Law & & & & $\begin{array}{l}217.5^{*} \\
(27.0)\end{array}$ & $\begin{array}{l}206.3^{*} \\
(22.2)\end{array}$ & $\begin{array}{l}147.7^{*} \\
(30.7)\end{array}$ & $\begin{array}{c}146.1^{*} \\
(26.3)\end{array}$ & $\begin{array}{r}150.5^{*} \\
(30.7)\end{array}$ \\
\hline Constant & $\begin{array}{c}443.6 * \\
(29.8)\end{array}$ & $\begin{array}{c}389.9 * \\
(25.3)\end{array}$ & $\begin{array}{c}381.5^{*} \\
(13.8)\end{array}$ & $\begin{array}{c}326.7^{*} \\
(18.4)\end{array}$ & $\begin{array}{l}327.2^{*} \\
(15.0)\end{array}$ & $\begin{array}{l}290.4^{*} \\
(29.5)\end{array}$ & $\begin{array}{c}309.6 * \\
(13.5)\end{array}$ & $\begin{array}{r}308.0^{*} \\
(14.7)\end{array}$ \\
\hline $\mathrm{R}^{2}$ & .57 & .74 & .73 & .53 & .69 & .82 & .81 & .81 \\
\hline
\end{tabular}

Some cultures are more oriented toward group rather than individual advancement in groups, such as the family or the business organization. Individual capability is less important in these cultures than the individual's willingness to follow the leader of the group. The statistical results in the various models show that students score lower on international tests in these societies. Implicitly, since scoring well on tests of individual skill is valued less highly, students, their families, and the schools exert less effort to achieve cognitive skills in these societies.

A long term orientation is critical for the achievement of high test scores. High scores at age 15 are the result of disciplined study from early childhood. Parents must sacrifice for a long time if their children are to attain this level of cognitive skills. 
The importance of Individualism for high test scores surges in the model once the Confucian dummy is added. Confucian countries are unusual in having low Individualism and high test scores, apparently due to the Confucian tradition of reliance on standardized testing for selecting government officials. In this model the Individualism and Long-Term Orientation cultural characteristics have a very large positive effect on average scores, while the Masculinity characteristic has a substantial negative effect on scores. Since the Scandinavian countries score low on the Masculinity index, this result likely is due to the relatively high test scores in these countries.

The results in model 2 suggest that there are two different cultural traditions that lead to high test scores. Western countries with a strong cultural belief in Individualism score highly because individual achievement is rewarded in these societies. East Asian societies do not have a strong belief in Individualism, but they have a tradition of standardized testing for the selection of employees, which also provides rewards for high test scores.

Column 3 shows that the three cultural characteristics and the dummy variable for Confucian tradition explain $73 \%$ of the variation in average scores across 58 countries. These results provide evidence that cultural characteristics largely determine a country's average scores on the PISA mathematics test.

Column 4 examines whether the Rule of Law index also explains average scores. The effect of this index on average scores is highly statistically significant. This single institutional characteristic explains 53\% of the variation in average scores, supporting Acemoglu, Gallego, and Robinson's argument that institutions determine a country's level of human capital.

Column 5 shows that when the Confucian tradition dummy is added, the Rule of Law and this tradition explain $69 \%$ of the variation in test scores across 60 countries. ${ }^{2}$ Column 6 presents the results when the six cultural characteristics and the one institutional characteristic are included in the model. In this model the Masculinity cultural characteristic loses its statistical significance, but the Individualism and Long-Term Orientation characteristics remain statistically significant at the $1 \%$ level and the explained variation in average test scores increases to $82 \%$.

Column 7 shows that four societal characteristics; Individualism, Long-Term Orientation, Rule of Law, and Confucian tradition explain $81 \%$ of the variation in average test scores across 58 countries. Column 8 shows the same model estimated using 2SLS and the World Bank Rule of Law index in 1996 as an instrument for the index in 2013. The results are similar, indicating that

\footnotetext{
${ }^{2}$ This sample size is slightly larger because two countries in the data set lack values for the longrun orientation cultural characteristic in the Hofstede data base.
} 
the OLS estimates of the model in column 7 are not biased due to the possible endogeneity of the Rule of Law index.

Table 2 presents the analysis that examines whether commitment to a major religion or to Confucian thought explains the cross-country variation in average test scores. Column 1 shows the effects of the three religions alone. These results summarize the difference in the average score associated with each religion, which explains $26 \%$ of the variation in average scores. Protestant affiliation raises average scores by 20 points while Catholic and Muslim affiliation lower average scores by 45 and 95 points, respectively. Adding the Confucian tradition raises the explained variation to $43 \%$ without changing the relative scores between the religious affiliations. The explained variation in this model is much lower than what was explained by the cultural beliefs and Rule of Law index in Table 1.

\section{Table 2}

The Effect of Religion on Average Test Scores (Dependent variable is the average score on PISA 2012 and/or 2015)

\begin{tabular}{|c|c|c|c|c|}
\hline & 1 & 2 & 3 & 4 \\
\hline Sample & 58 & 58 & 56 & 56 \\
\hline Protestant & $\begin{array}{c}20.1 \\
(26.1)\end{array}$ & $\begin{array}{l}63.6^{* *} \\
(25.8)\end{array}$ & $\begin{array}{c}30.0 \\
(19.7)\end{array}$ & $\begin{array}{c}-5.2 \\
(17.7)\end{array}$ \\
\hline Catholic & $\begin{array}{c}-45.3 * * \\
(19.3)\end{array}$ & $\begin{array}{c}-3.0 \\
(20.4) \\
\end{array}$ & $\begin{array}{c}5.2 \\
(14.5)\end{array}$ & $\begin{array}{c}-7.8 \\
(12.2)\end{array}$ \\
\hline Muslim & $\begin{array}{l}-94.9 * \\
(28.5) \\
\end{array}$ & $\begin{array}{l}-51.2 \\
(27.8) \\
\end{array}$ & $\begin{array}{l}-23.9 \\
(21.5) \\
\end{array}$ & $\begin{array}{l}-26.5 \\
(17.6) \\
\end{array}$ \\
\hline Individualism & & & $\begin{array}{l}110.2^{*} \\
(21.6)\end{array}$ & $\begin{array}{c}44.4^{* *} \\
(22.1)\end{array}$ \\
\hline Long Term Orientation & & & $\begin{array}{l}77.7^{*} \\
(21.2) \\
\end{array}$ & $\begin{array}{l}72.8^{*} \\
(16.6) \\
\end{array}$ \\
\hline Confucian Tradition & & $\begin{array}{l}83.1^{*} \\
(21.4) \\
\end{array}$ & $\begin{array}{l}86.9 * \\
(16.8) \\
\end{array}$ & $\begin{array}{l}53.8^{*} \\
(15.3) \\
\end{array}$ \\
\hline Rule of Law & & & & $\begin{array}{l}145.9 * \\
(29.3)\end{array}$ \\
\hline Constant & $\begin{array}{c}494.5^{*} \\
(13.6)\end{array}$ & $\begin{array}{c}457.6^{*} \\
(15.4) \\
\end{array}$ & $\begin{array}{c}366.3^{*} \\
(16.2) \\
\end{array}$ & $\begin{array}{l}318.2 * \\
(16.5) \\
\end{array}$ \\
\hline $\mathrm{R}^{2}$ & .26 & .43 & .74 & .83 \\
\hline
\end{tabular}

When the two cultural beliefs, Individualism and Long-term orientation, are added to the model in column 3, the effects of the religions decline and become statistically insignificant. When the Rule of Law index is added in column 4, the effects of the three religions diminish 
further. The effect of affiliation to Islam still lowers scores by 27 points, but this effect is not statistically significant. These results indicate that the Hofstede cultural characteristics and the Rule of Law institutional characteristic are the more valid determinants of the variation in average scores.

If cultural and institutional characteristics are the fundamental causes of average test scores, then they must continue to be statistically significant in a model that includes the proximate causes. Table 3 shows model results beginning with variables for the proximate causes and then adding the variables for the more fundamental cultural and institutional causes.

\section{Table 3}

Effect of Family and School Characteristics, Culture, and Institutions on Average Scores (Dependent variable is average score on PISA 2012 and/or 2015)

\begin{tabular}{|c|c|c|c|c|c|c|c|}
\hline & 1 & 2 & 3 & 4 & 5 & 6 & 7 \\
\hline Sample & 57 & 56 & 57 & 57 & 57 & 56 & 56 \\
\hline $\begin{array}{l}\text { Adult Avg. Schooling at } \\
\text { Age } 35-40\end{array}$ & $\begin{array}{l}16.9^{*} \\
(2.9)\end{array}$ & $\begin{array}{l}14.2^{*} \\
(2.9)\end{array}$ & $\begin{array}{l}14.6^{*} \\
(2.9)\end{array}$ & $\begin{array}{l}11.1^{*} \\
(2.1)\end{array}$ & $\begin{array}{l}8.4^{*} \\
(2.0)\end{array}$ & $\begin{array}{c}4.8 * * \\
(2.3)\end{array}$ & $\begin{array}{c}4.8 * * \\
(2.3)\end{array}$ \\
\hline $\begin{array}{l}\text { Pupil-Teacher Ratio in } \\
\text { Primary School }\end{array}$ & $\begin{array}{l}-3.42^{*} \\
(1.28) \\
\end{array}$ & $\begin{array}{l}-1.40 \\
(1.42)\end{array}$ & $\begin{array}{l}-1.48 \\
(1.39)\end{array}$ & $\begin{array}{l}-2.71 * \\
(1.00)\end{array}$ & $\begin{array}{r}-1.52 \\
(.94) \\
\end{array}$ & $\begin{array}{r}-1.22 \\
(.90)\end{array}$ & \\
\hline $\begin{array}{l}\text { School Resources (\% of } \\
\text { GDP/child pop share) }\end{array}$ & & $\begin{array}{l}2.28^{* *} \\
(.92)\end{array}$ & $\begin{array}{c}2.22^{* *} \\
(.92)\end{array}$ & $\begin{array}{l}2.63^{*} \\
(.65)\end{array}$ & $\begin{array}{l}1.86^{*} \\
(.61)\end{array}$ & $\begin{array}{l}1.71^{*} \\
(.59)\end{array}$ & $\begin{array}{l}1.94^{*} \\
(.57)\end{array}$ \\
\hline Central Exit Exam & $\begin{array}{c}15.2 \\
(12.1) \\
\end{array}$ & $\begin{array}{c}17.0 \\
(11.5) \\
\end{array}$ & $\begin{array}{c}13.1 \\
(10.6) \\
\end{array}$ & $\begin{array}{c}4.2 \\
(7.6) \\
\end{array}$ & $\begin{array}{l}10.2 \\
(7.0) \\
\end{array}$ & $\begin{array}{l}11.6 \\
(6.7) \\
\end{array}$ & $\begin{array}{l}11.9 \\
(6.7) \\
\end{array}$ \\
\hline $\begin{array}{l}\text { Private Share of } \\
\text { Secondary Enrolment }\end{array}$ & $\begin{array}{c}22.1 \\
(34.2)\end{array}$ & $\begin{array}{c}17.5 \\
(32.5)\end{array}$ & & & & & \\
\hline Rule of Law & & & & & $\begin{array}{l}90.7^{*} \\
(23.9) \\
\end{array}$ & $\begin{array}{l}89.1^{*} \\
(28.0) \\
\end{array}$ & $\begin{array}{l}100.2^{*} \\
(27.0) \\
\end{array}$ \\
\hline Individualism & & & & & & $\begin{array}{c}26.3 \\
(18.6) \\
\end{array}$ & $\begin{array}{c}27.1 \\
(18.7) \\
\end{array}$ \\
\hline $\begin{array}{l}\text { Long Term } \\
\text { Orientation }\end{array}$ & & & & & & $\begin{array}{c}30.1 \\
(16.0)\end{array}$ & $\begin{array}{l}33.2^{* *} \\
(16.0)\end{array}$ \\
\hline $\begin{array}{l}\text { Confucian } \\
\text { Tradition }\end{array}$ & & & & $\begin{array}{l}75.8^{*} \\
(10.5) \\
\end{array}$ & $\begin{array}{c}68.4^{*} \\
(9.5) \\
\end{array}$ & $\begin{array}{l}67.6^{*} \\
(12.0) \\
\end{array}$ & $\begin{array}{l}64.2^{*} \\
(11.8)\end{array}$ \\
\hline Constant & $\begin{array}{c}314.7^{*} \\
(43.9)\end{array}$ & $\begin{array}{l}267.5^{*} \\
(45.6) \\
\end{array}$ & $\begin{array}{c}270.8^{*} \\
(45.7)\end{array}$ & $\begin{array}{l}318.3^{*} \\
(33.1) \\
\end{array}$ & $\begin{array}{r}284.0^{*} \\
(30.8) \\
\end{array}$ & $\begin{array}{l}297.6 * \\
(30.0) \\
\end{array}$ & $\begin{array}{r}265.8^{*} \\
(18.8) \\
\end{array}$ \\
\hline $\mathrm{R}^{2}$ & .59 & .63 & .62 & .81 & .85 & .87 & .87 \\
\hline
\end{tabular}

As mentioned earlier, Fuchs and Woessmann [2007] attribute cross-country differences in average PISA scores to differences in family characteristics, school resources, and school system characteristics. Column 1 shows the results with a model that includes four variables that 
represent these three proximate factors: the average level of adult schooling (age 35-40), the pupil-teacher ratio in primary school, the existence of a central exit exam, and the private share of secondary school enrollment. These proximate causes explain $59 \%$ of the variation in the average scores, although the central exit exam and the private share of secondary enrollment are not statistically significant.

Column 2 shows the results when the variable for pre-tertiary public expenditures/student is added to the model. This variable is highly statistically significant and raises the explained variation in the model to $63 \%$, but it greatly reduces the effect and the statistical significance of the pupil-teacher ratio.

Column 3 shows the results when the private share of secondary school enrollment is removed, since it has very low statistical significance. The central exit exam and the pupil-teacher ratio have noticeable effects, but they are not statistically significant at the $5 \%$ level. Still, the four proximate factors in this model explain $62 \%$ of the variation in average test scores across countries.

The four family, school, and school system characteristics in column 3 cannot explain the very high average scores in the East Asian countries that have a Confucian tradition. Column 4 shows the results when a dummy variable for this tradition is added to this model. This variable has a huge effect that is highly statistically significant, and it raises the explained variation in average test scores to $81 \%$. This model provides very strong evidence for the importance of culture in the determination of average test scores.

Column 5 shows the results when the Rule of Law index is added to the model. Even with the other proximate causes still in the model, the Rule of Law has a huge, highly statisticallysignificant effect. With this variable included, the explained variation in average scores rises to $85 \%$.

Column 6 shows the results when the two most important cultural characteristics are included in the model. These variables raise the total explained variation to $87 \%$, but they are not statistically significant at the $5 \%$ level. With the inclusion of the cultural and institutional variables, the effect of parental schooling becomes much smaller and is only statistically significant at the $5 \%$ level.

Overall the effect of parental schooling on average scores declines by $67 \%$ when cultural and institutional characteristics are included in the model. These results indicate that a large share of the effect of parental schooling on average scores is a proxy for the cultural and institutional causes of higher scores, which raise a society's average level of schooling. 
In the complete model the effect of the central exit exam increases to ten points, and it becomes more statistically significant, but it still does not achieve significance at the $5 \%$ level. The existence of this exam is relatively common across the countries in the data set, as over $70 \%$ of the 60 countries require it. It may be that some countries have adopted the exam because it has become the fashion in educational circles to do so, even though the country does not have the cultural characteristics required to use the scores from this exam for some practical purpose.

Since the independent variables have different magnitudes, the magnitude of their estimated effects does not indicate their relative importance in determining average scores. Table 4 shows the effect on average scores of changes in each input variable from its minimum to its maximum value for three models with different mixes of fundamental and proximate causes. The interpretation of the results in this table provides a guide to the relative importance of the various cultural and other national characteristics in explaining differences in average PISA test scores between countries. It also provides an indication of how much changes in certain characteristics might enable countries to raise their scores.

The maximum variation in the input variables for the model with the four proximate causes changes average scores by 202 points. The maximum variation in the input variables in the model with the four fundamental causes changes average scores by 241 points. Clearly the fundamental causes explain far more of the cross-country variation in average scores than the traditional proximate causes.

Table 4

Effect of Culture and Institutions on Average Test Scores

(Dependent variable is average score on PISA 2012 and/or 2015)

\begin{tabular}{|c|c|c|c|c|c|c|c|c|c|}
\hline & \multicolumn{2}{|c|}{ Input Values } & \multicolumn{2}{|c|}{$\begin{array}{c}\text { Proximate } \\
\text { Causes }\end{array}$} & \multicolumn{2}{|c|}{$\begin{array}{c}\text { Fundamental } \\
\text { Causes }\end{array}$} & \multicolumn{3}{|c|}{$\begin{array}{c}\text { Prox. \& Fundamental } \\
\text { Causes }\end{array}$} \\
\hline & Min & Max & Effect & Points & Effect & Points & Effect & Points & Share \\
\hline Parents Schooling & 7.0 & 14.0 & 14.6 & 102.2 & & & 4.8 & 33.6 & \\
\hline School Resources & 5.8 & 34.5 & 2.22 & 63.7 & & & 1.94 & 55.7 & \\
\hline Pupil-Teacher Ratio & 8.4 & 23.6 & -1.48 & 22.5 & & & & & \\
\hline Central Exit Exam & 0.0 & 1.0 & $13.1^{*}$ & 13.1 & & & $11.9 *$ & 11.9 & \\
\hline Subtotal & & & & 201.5 & & & & 101.2 & .37 \\
\hline Confucian Trad & 0.00 & 1.00 & & & 60.2 & 60.2 & 64.2 & 64.2 & \\
\hline Rule of Law & 0.34 & 0.89 & & & 146.1 & 80.4 & 100.2 & 55.1 & \\
\hline Individualism & 0.13 & 0.91 & & & 48.3 & 37.7 & $27.1^{*}$ & 21.1 & \\
\hline LT Orientation & 0.13 & 1.00 & & & 72.5 & 63.1 & 33.2 & 28.9 & \\
\hline Subtotal & & & & & & 241.4 & & 169.3 & .63 \\
\hline Total & & & & 201.5 & & 241.4 & & 270.5 & \\
\hline
\end{tabular}


When both sets of causes are in the model, the maximum variation in all the causes changes average scores by 271 points, which is 29 points more than the fundamental causes alone. In this model the variation in the fundamental causes explains $63 \%$ of the variation in average scores and the variation in the proximate causes explains $37 \%$ of the variation in the average scores. The most important proximate cause in the mixed model is the level of financial resources provided to schools.

Hanushek and Woessmann [2008] argue that just providing more resources to schools will not reliably lead to improved student performance when the institutional structure is not changed. This may be true in rich countries, but for poor countries the results here suggest the opposite. After controlling for cultural factors, increasing public funding for schools is the only policy option identified here that is associated with substantially higher average scores (55 points).

Even this effect may be politically impossible to achieve because only countries with certain cultural and institutional characteristics are willing to provide substantial public resources to schools. Another regression (not shown) reveals that about $50 \%$ of the variation in the public resources provided to schools is explained by cultural and institutional characteristics, which means that only half of the 86 points attributed to variations in public resources in the model of proximate causes (i.e., 43 points) are not culturally determined. It is not clear if even this level of improvement could occur quickly, since the cross-sectional analysis is this study is implicitly measuring a log-run effect.

Fuchs and Woessmann [2007] ascribe great value to the adoption of a central exit exam as a means to raise average scores. The results in this analysis provide some support for their conclusion, but the effect is only significant at the $10 \%$ level. Rather the results suggest that cultural and institutional changes in the society are required to substantially raise these scores. According to this analysis, the adoption of a central exit exam might raise average scores by 12 points, but the existence of a Confucian tradition that ties advancement in society to the achievement of high scores on this exam raises average scores by 64 more points. Absent this tradition, the effect of a central exit exam seems quite limited.

These results indicate that schools are relatively limited in their capability to independently raise students' average test scores. An increase in school resources or in adults' average level of schooling can raise these scores, but societies' willingness to provide more resources to raise average schooling and average test scores is itself culturally and institutionally constrained.

At the beginning of the article, reference was made to the difference in scores between Singapore (569) and the Dominican Republic (328). Except for the Individualism trait, in which 
both countries score low, these two countries are generally at the opposite ends of the range of input values shown in Table 3. Singapore has higher average scores primarily because of its Confucian tradition, its much higher commitment to the Rule of Law, its Long Term Cultural Orientation, and its much higher average level of adult schooling. Singapore also expends a higher share of its GDP on public education, but more importantly, the share of its population under 15 years of age is only half as large as in the Dominican Republic, so Singapore's share of GDP expended per student is much higher. In addition, parents in Singapore often augment the higher public expenditure/student with their own expenditures on private tutoring, which is not common in the Dominican Republic [Dang and Rogers, 2008].

The Dominican Republic has the lowest reported expenditures on public education as a share of GDP (2.1\% in 2007) of the 60 countries included in the data set. According to the model results, this is one of the few areas where a change in education policy might have a substantial positive effect on students' average test scores. The adoption of a central exit exam also might have a positive effect, but the empirical results indicate that this policy (alone) is not a reliable strategy for raising students' average scores.

\section{Conclusions}

Researchers have performed many studies that attribute the differences in international test scores to student, family, school, and school system characteristics. These studies do not explain why these characteristics vary so much across countries.

Institutionalists argue that the level of human capital in each country has both proximate and fundamental causes. Family, school, and school system characteristics are the proximate causes of a country's level of human capital, but cultural and institutional characteristics are the fundamental causes.

In this analysis I examine the effect of various proximate and fundamental causes on students' average scores on the PISA 2012 and/or 2015 mathematics test. I show that while a number of family, school, and school system characteristics can explain $62 \%$ of the variation in average scores across 57 countries, cultural and institutional characteristics can explain $81 \%$ of this variation. Adding the proximate causes to the model of fundamental causes only raises the explained variation in average scores by $6 \%$.

I find little evidence that changes in school system characteristics affect average scores. The private share of enrollment in secondary school has no effect on average scores. The existence of a central exit exam is associated with a 12-point increase in average scores, but this effect is only statistically significant at the $10 \%$ level. 
I find a substantial, very statistically significant effect from additional public expenditures on pre-tertiary schooling. After controlling for cultural characteristics, variations in this indicator account for a 56-point difference in average scores. But it is not clear that achieving this level of improvement is feasible across countries because the evidence also indicates that whether countries are willing to provide these resources is itself culturally-determined.

In contrast, I find that three cultural characteristics and one institutional characteristic explain $81 \%$ of the variation in average scores. The Confucian tradition explains 60 points. Differences in countries' commitment to the Rule of Law explains 80 points. Cultural differences in beliefs with respect to individualism vs. collectivism and a long-run vs. a short-run orientation explain another 100 points.

These results reveal the importance of student and family motivation in the achievement of high test scores. Achievement of these scores is difficult, so students and their families only make the commitment to achieve high scores in societies that provide considerable rewards for their achievement or considerable penalties for the failure to achieve them. Absent this student and family motivation to achieve high scores, schools and school systems are extremely limited in how much they can raise student scores. Schools and families, in turn, operate as agents of the larger society. They respond to societal incentives with respect to the student achievement of cognitive skills. Average scores are much higher in countries that ascribe more importance to the achievement of cognitive skills.

The results in this analysis indicate that over time cultural and institutional factors largely determine students' average scores on standardized tests. If governments in countries with low average scores want to raise these scores, they need to focus their attention on changing the weak incentives for student achievement in their societies. The results here indicate that they will have to increase the societal rewards for student achievement if they wish to see substantial improvement in students' average scores.

These findings also may explain why in countries with numerous subcultures, students in some ethnic groups consistently score higher on standardized tests than students in other ethnic groups, even though they attend the same schools. Implicitly, the subcultures of the ethnic groups with the higher average scores ascribe more value to the achievement of high scores than the subcultures of the other groups, so in these subcultures families make more effort to assist (or pressure) their students to achieve higher scores. 


\section{References}

Acemoglu, Daron, Gallego, Francisco A., and Robinson, James A., 2014, "Institutions, Human Capital, and Development," Annual Review of Economics, v6, 875-912

Acemoglu, Daron, Johnson, Simon, and Robinson, James A., 2005, "Institutions as a Fundamental Cause of Long-Run Growth," in Aghion, Philippe, and Durlauf, Steven N., Handbook of Economic Growth, Volume 1A, Elsevier, Amsterdam

Barrett, David, 1982, World Christian Encyclopedia: A Comparative Study of Churches and Religions in the Modern World, AD 1900 - 2000, Oxford University Press, New York

Barro, Robert and Jong-Wha Lee, 2013, "A New Data Set of Educational Attainment in the World, 1950-2010." Journal of Development Economics, vol 104, pp.184-198.

Bol, Thijs, Witschge, Jacqueline, Van de Werfhorst, Herman G., and Dronkers, Jaap, 2014, "Curriular Tracking and Central Examinations: Counterbalancing the Impact of Social Background on Student Achievement in 36 Countries," Social Forces, June, 1545-1572

Bowen, James, 1986, A History of Western Education, Volume 3, The Modern West: Europe and the New World, St. Martin's Press, New York

Breton, Theodore R., 2013, "The Role of Education in Economic Growth: Theory, History, and Current Returns," Educational Research, v55, n2, 121-138

Breton, Theodore R., 2015, "Higher Test Scores or More Schooling? Another Look at the Causes of Economic Growth," Journal of Human Capital, v9, n2, 239-263

Breton, Theodore R. and Canavire-Bacarreza, Gustavo, 2017, "Low Test Scores in Latin America: Poor Schools, Poor Families, or Something Else?" Compare: A Journal of Comparative and International Education, forthcoming

Dang, Hai-Anh, and Rogers, F. Halsey, 2008, "The Growing Phenomenon of Private Tutoring: Does It Deepen Human Capital, Widen Inequalities, or Waste Resources?," The World Bank Research Observer, v23, n2, 161-200

Easterlin, Richard A., 1981, "Why Isn't the Whole World Developed?" The Journal of Economic History, v41, n1, 1-19

French, Joseph J., French, Atchaporn, and Li, Wei-Xuan, 2015, "The relationship among cultural dimensions, education expenditure and PISA performance," International Journal of Educational Development, v44, 25-34

Fuchs, Thomas, and Woessmann, Ludger, 2007, "What accounts for international differences in student performance? A re-examination using PISA data," Empirical Economics, v32, 433-464 
Hanushek, Eric A. and Woessmann, Ludger, 2008, "The Role of Cognitive Skills in Economic Development," Journal of Economic Literature, v46, n3, 607-668

Hanushek, Eric A. and Woessmann, Ludger, 2012b, "Do Better Schools Lead to More Growth?

Cognitive Skills, Economic Outcomes, and Causation," Journal of Economic Growth, 17, 267-

\section{1}

Heston, Alan, Summers, Robert, and Aten, Bettina, 2012, Penn World Table Version 7.1, Center for International Comparisons of Production, Income and Prices at the University of Pennsylvania

Hofstede, Geeet, and Hofstede, Gert Jan, 2005, Cultures and Organizations, Software of the Mind, McGraw-Hill, New York

Juerges, Hendrik, and Schneider, Kerstin, 2004, "International Differences in Student Achievement: An Economic Perspective," German Economic Review, v5, n3, 357-380

Klasing, Mariko, 2013, "Cultural dimensions, collective values and their importance for institutions," Journal of Comparative Economics, v41, 447-467

La Porta, Rafael, Lopez-de-Silanes, Florencio, Shleifer, Andrei, and Vishny, Robert, 1999, "The Quality of Government," Journal of Law, Economics, and Organization, v15, n1, 222-282

Leschnig, Lisa, Schwerdt, Guido, and Zigova, Katarina, 2016, “Central School Exams and Adult Sills: Evidence from PIAAC," University of Konstanz, Working paper

Licht, Amir N., Goldschmidt, Chanan, and Schwartz, Shalom H., 2007, "Culture rules: The foundations of the rule of law and other norms of governance," Journal of Comparative Economics, v35, 659-688

North, Douglass C., 1990, Institutions, Institutional Change, and Economic Performance, Cambridge University Press, New York

North, Douglass C., and Thomas, Robert Paul, 1973, The Rise of the Western World, A New Economic History, Cambridge University Press, New York

Zhang, Liang, Khan, Gulab, and Tahirsylaj Armend, 2015, "Student performance, school differentiation, and world cultures: Evidence from PISA 2009," International Journal of Educational Development, v42, 43-53 